$\underline{\text { Reports }}$

\title{
Re-emergence of mucormycosis in COVID-19 recovered patients transiting from silent threat to an epidemic in India
}

\author{
Mahnoor Sukaina ${ }^{1}$ (1) \\ 1 Karachi Medical and Dental College, Karachi, Pakistan \\ Keywords: covid-19, black fungus, mucormycosis \\ https://doi.org/10.29392/001c.25479
}

\section{Journal of Global Health Reports}

Vol. 5, 2021

COVID-19 cases in India are approaching 30 million while the death has surpassed 385,167 on June 18,2021 , 1 with a record of 4205 deaths on Wednesday, May 14, 2021, ${ }^{2}$ a few weeks after the health minister of India declared "endgame" for the COVID-19 pandemic in the country. ${ }^{3}$ India is battling through the second wave with two mutant variants B.1.617.2 and B.1.1.7 challenging their healthcare system, ${ }^{3}$ meanwhile, World Health Organization (WHO) has shown austerity regarding the strain B.1.617.2 and on May 09, 2021, classified it as a "variant of concern", 4 which has already transmitted to 44 countries until May $13,2021 .^{2}$ India with the population of 1.4 billion, experts believe that the actual COVID-19 figures will be five to ten times more than the official figure, with cases approaching nearly 400,000 a day..$^{5}$ The hospitals have nearly run out of beds, patients queuing up for 12 hours for the availability of a bed, ${ }^{6}$ and daily oxygen supply of 50,000 tonnes needed to combat hypoxic condition of COVID-19 patients in India, ${ }^{7}$ as India is reaching a "covid-hell". 3

\section{WHAT IS MUCORMYCOSIS AND HOW DOES IT TRANSMIT?}

Amid the catastrophic situation of the COVID-19 pandemic in India, the re-emergence of a high mortality mucormycosis infection; a 'black fungus' among COVID-19 patients or recovered COVID-19 patients is posing a serious and unforeseen health threat in India. According to the reference to the experts, Kaul (2021) reports that Mucormycosis has become an epidemic. 8

\section{CLINICAL FORMS OF MUCORMYCOSIS}

Mucorales fungi are seen as aseptate hyphae, with some 11 genera and 27 species are known to cause human infection. Mucormycosis belongs to class Phycomycetes which is subdivided into genera Absidia, Rhizopus, and Mucor. ${ }^{9}$ Prakash and Chakrabarti (2021) mention the presence of pathogenic species including Rhizomucor, Rhizopus, Apophysomyces Lichtheimia, and, Cunninghamella in Indian soil. ${ }^{10}$ Prakash et al. (2019) discussed that the global leading species to cause mucormycosis is Rhizopus arrhizus, while, Apophysomyces variabilis, is the second most common causative agent in India, along with the presence of other agents in India including Rhizopus homothallicus, Thamnostylum lucknowense, and Mucor irregularis. ${ }^{11}$

\section{TRANSMISSION OF THE DISEASE}

Mucormycosis is caused by the fungus mucor that requires a wet surface to adhere, therefore, a humid environment is an ideal condition for it to prevail. ${ }^{12}$ It could transmit through the hospital bed linen, unsterilized oxygen pipes, and hospital ventilators. ${ }^{12}$ Mucormycosis infection targets immunocompromised patients, low levels of neutrophils, cancer patients, organ transplants, and patients who underwent stem cell transplants. ${ }^{13}$ Steroids are used for the treatment of COVID-19 infections while heavy steroid use induces immunosuppression can potentially increase chances of opportunistic infection of which is mucormycosis. ${ }^{13}$ The spores are commonly found in organic matter particularly food, soil, and plants which require humidity to grow. ${ }^{13}$ The inhaled spore forms hyphae that invade the paranasal sinuses, extending further through anatomical sites within the skull causing rhino-orbital or rhino-cerebral infection. COVID-19 patients are highly susceptible to develop opportunistic mucormycosis, due to weakened immune systems by decreased levels of CD4+T and CD8+T cells. ${ }^{13,14}$ Other factors that increase the vulnerability of COVID-19 patients include prolonging hospital stay, iatrogenic corticosteroid therapy with uncontrollable diabetes mellites, and diabetic ketoacidosis. ${ }^{13}$ and pulmonary infections. ${ }^{8}$ In India, the usual time to fumigate ICU is around 14 days, however, due to COVID-19, complete fumigation remains a challenge at large. ${ }^{15}$

\section{SYMPTOMS OF MUCORMYCOSIS}

Indian Council of Medical Research (ICMR) has released signs and symptoms of mucormycosis that may include pain and redness around the eyes and nose, cough, fever, headache, disorientation, dyspnea, hematemesis, sinusitis, toothache, facial pain and numbness, hemoptysis, blackish discharge from nose and visual disturbances including unspecified vision loss. ${ }^{16}$ ICMR has given strict instructions that any patient experiencing the mentioned symptoms must immediately seek the medical attention.

Prakash and Chakrabarti (2021) discussed the anatomical localization of mucormycosis with rhino-orbital-cerebral (ROCM) commonest area, followed by cutaneous, pulmonary, renal, gastrointestinal, disseminated, breast, ear, spine, heart, and bone. ${ }^{10}$ In a study conducted by Pagano et al. (1997) through eighteen hematology departments, fever, 
thoracic pain, cough, and shortness of breath were the main symptoms presented in the patient, while $89 \%$ of the patients were neutropenic at the time of onset. ${ }^{9}$ Talmi et al. (2002) found bloody nasal discharge and black nasal eschar as a sign of the infection, meanwhile, malaise was seen as the most common symptom in $89 \%$ of the cases. ${ }^{17}$

\section{MUCORMYCOSIS IN PRE-COVID-19 AND DURING COVID-19}

In the Pre-COVID-19 era, Prakash et al. (2019) discussed hematological malignancies to be the foremost global indicator for mucormycosis infection, while, diabetes mellitus was the forerunner reason the cases in India. ${ }^{11}$ Other comorbid conditions involve skin trauma, human immunodeficiency virus, peritoneal dialysis, iron overload, deferoxamine therapy, illicit drug infusion, and voriconazole therapy. ${ }^{10}$ Pagano et al. (1997) found the lungs to be the most affected site for the infection, followed by chronic nerve compression, sinus, liver, kidney, heart, orbital space, and large intestine. ${ }^{9}$ However, currently in the mucormycosis epidemic in India, orbital space is the common site of infection followed by other organs.

\section{PROGNOSIS AND OUTCOMES}

\section{OUTCOME OF INFECTION}

In the study conducted by Pagano et al. (1997), the outcome of the infection resulted in thirty patients dying within 3 months of the treatment, out of which, 28 died due to mucormycosis. ${ }^{9}$ Talmi et al. (2002) discussed the orbital compromise exhibits the advancement of the fungal infection into cranial fossa leading to the option of orbital exenteration, however, this may lead to mutilation and irreversible loss of vision. ${ }^{17}$

\section{PROGNOSTIC FACTORS}

Pagano et al. (1997) found Phycomycetes to be resistant to triazoles and nystatin. ${ }^{9}$ Pagano et al. (1997) found the increase in neutrophils after post-chemotherapy aplasia and amphotericin B treatment was closely associated with the prognosis from the infection. ${ }^{9}$ However, oral antimycotic prophylaxis failed to prevent mucormycosis. ${ }^{9}$ Controlling the environmental exposure to neutropenic patients showed positive outcomes in restricting the development of filamentous fungal infection. Isavuconazole is a new antifungal remedy for the treatment of mucormycosis, which was unavailable in India in 2018, but recently introduced in India, therefore, it lacks research on the efficacy in longterm, however, during the limited timeframe, it has shown efficacy as compared to amphotericin B. ${ }^{11}$ Talmi et al. (2002) noted palatal involvement in the patients with poor prognosis. Talmi et al. (2002) discussed the use of granulocyte colony-stimulating factor (G-CSF) in neutropenic patients to hold value. ${ }^{17}$

\section{MORTALITY RATE}

Before COVID-19 the mortality rate from mucormycosis in
India was $46.7 \%$, where, the mortality rate in North India was higher compared to South India. ${ }^{11}$ Prakash and Chakrabarti (2021) discussed that the mortality rate in the clinical presentation of mucormycosis is $64-97 \%$ in patients with gastrointestinal comorbidity, 61-77\% in pulmonary, $62-79 \%$ in disseminated, $31-49 \%$ in ROCM, 23-57\% in cutaneous cases. ${ }^{10}$

\section{INCIDENCE AND PREVALENCE OF MUCORMYCOSIS}

There is a rise in mucormycosis cases globally, the rate of infection is further higher in developing countries including India. ${ }^{18}$ Prakash and Chakrabarti (2021) debated on the exact incidence of mucormycosis in India due to a deficit in a population-based study, however, with the aid of the computational-model-based method, the prevalence is 14 cases per 100,000 in India. ${ }^{10}$ Prakash and Chakrabarti (2021) in their research discussed that prevalence of mucormycosis is 70 times higher in India as compared to global. ${ }^{10}$ It was 13 cases per year from 1990 to 1999, 36 annual cases from 2000 to 2004, 50 annual cases from 2006 to 2007, and 89 annual cases from 2013 to $2015 .{ }^{10}$ One reason Prakash and Chakrabarti (2021) discussed is improvement in the diagnosis of the disease. ${ }^{10}$ In other studies, discussed by Prakash and Chakrabarti (2021) the yearly incidence is 18 cases in Southern India (Tamilnadu) from 2005 to 2015, while, 9.5 cases from 2015 to $2019 .{ }^{10}$ Talmi et al. (2002) mention that seasonal presence may contribute towards the incidence with the peak in fall and early winter. ${ }^{17}$

\section{RISE IN THE CASES OF MUCORMYCOSIS}

Mucormycosis has a mortality rate of around 50 percent ${ }^{12}$ and is costly to treat, which can further burden the health care infrastructure suffering from deficient and exhaustive resources. According to the report published in the Guardian, there were 300 cases of mucormycosis in Gujarat until May 13, 2021, ${ }^{19}$ which exponentially increased to 2,859 cases in Gujarat until May 26, 2021, ${ }^{20}$ marking over $850 \%$ increase in less than two weeks. In Gujarat 8 COVID-19 recovered patients lost their eyesight due to mucormycosis. $^{21}$ similarly, 200 COVID-19 survivors are being treated for mucormycosis in Maharashtra of which 8 had died. ${ }^{21} 58$ cases from Mumbai, Pune, Delhi, Hyderabad, and Bangalore have been reported between December and February about two weeks of COVID-19 recovery. ${ }^{22}$ In Mumbai, 11 out of 40 infected individuals went through enucleation due to the extensive involvement of fungus in the orbit. ${ }^{22}$ whereas, some Indian states are at high risk of a surge in cases around 100-200 percent. ${ }^{15}$ 2,770 cases for mucormycosis are recorded in Maharashtra, 768 in Andhra Pradesh, 752 in Madhya Pradesh, and 744 in Telangana, while a total of 11,717 cases are detected in India as of May 27, 2021 20 ; which is three times more than found in a decade in Europe, ${ }^{23}$ while there were only 29 cases of mucormycosis in March of this year in India. ${ }^{24}$ The cases further rose to 28,000 according to a report, ${ }^{25}$ while, cases are on the rise with 2,856 cases reported in Karnataka. ${ }^{26}$ A study by Sharma et al. (2021) conducted in Jaipur, India, among 23 
COVID-19 recovered patients from August to December, the rhino-orbital fungal infection mainly starts in ethmoidal sinus then proceed to the maxillary sinus, all patients received corticosteroids for COVID-19 and the majority of 21 patients were diabetic indicating a major link with diabetes mellitus. ${ }^{13}$ According to WHO, around $8.7 \%$ population in India are diabetic, and with inevitability to use steroids for the treatment of COVID-19 makes them susceptible to contact with mucormycosis. ${ }^{27}$

\section{WAS IT THE CASE OF AN EMERGING PATHOGEN, RISE DURING THE COVID-19?}

Mucormycosis is not a new infection, neither it has been reported recently. It had its presence but the condition remained as rare. ${ }^{9,10,17}$ However, the steroid treatment in COVID-19 patients is causing an immunosuppressed condition, together with the conditions in which mucormycosis infects humans.

\section{COSTS, EFFORTS, AND TREATMENT OF MUCORMYCOSIS}

Immediate efforts are being made by Gujrat state, by an immediate supply of 5000 doses of Amphotericin b worth Indian Rupees 3.12 crore $^{21}$ (approx. US $\$ 425,000$ ) and allocating 60 beds each in two separate wards. ${ }^{28}$ The antifungal I/ $\mathrm{V}$ treatment is the only treatment that costs around Indian Rupees 196,000 (US\$2,688) per patient. ${ }^{22}$ Amphotericin b is nephrotoxic, which leads to kidney damage. ${ }^{8}$ ICMR has released advisory guidelines to inhibit the spread of mucormycosis, encouraging COVID-19 patients to keep glucose level under control, usage of sterile water, and cautious usage of steroids, while, prohibiting patients to ignore symptoms of mucormycosis, and seeking medical help as appropriate. ${ }^{16}$

\section{DO CASES DECLINE AS THE COVID-19 SITUATION IMPROVES?}

Given the current scenario, it is difficult to suggest that whether a decline in COVID-19 cases may bring improvement in the cases of mucormycosis. According to the expert prediction, India is expected to be hit by the third COVID-19 wave by October, ${ }^{29}$ and the possibility of a new mutant variant may result in a completely unknown situation. The use of steroids, along with the comorbid conditions, may still pose a serious health risk of mucormycosis among the COVID-19 recovered patients.

\section{CONCLUSIONS}

The burden of COVID-19 in India has affected millions, which has been an emergency throughout the country during the second wave. The mucormycosis infection has been declared an epidemic in India due to the increased vulnerability of COVID-19 recovered patients with corticosteroid therapy and diabetes mellitus. Since the treatment is expensive, the burden of infection is increased on the health care system. The mortality rate of mucormycosis is much higher than of COVID-19 infection alone. Since the world has a greater population of diabetic patients in most regions and steroid therapy being used as a potential drug for COVID-19 infection, the warmer and humid regions where COVID-19 and diabetes are prevailing can be an immediate health hazard, especially in low-income and middle-income countries.

\section{FUNDING}

None.

\section{AUTHORSHIP CONTRIBUTIONS}

Mahnoor Sukaina is the sole author.

\section{COMPETING INTERESTS}

The author completed the Unified Competing Interest form at www.icmje.org/coi_disclosure.pdf (available upon request from the corresponding author) and declare no conflicts of interest.

\section{CORRESPONDENCE TO:}

Mahnoor Suakina, Karachi Medical and Dental College, D-35/2 Block-1, Clifton. msukainavazir193@gmail.com

Submitted: June 05, 2021 GMT, Accepted: June 23, 2021 GMT 


\section{REFERENCES}

1. WHO. COVID-19 Dashboard. Accessed June 18, 2021. https://covid19.who.int/region/searo/country/i $\underline{\mathrm{n}}$

2. Fox K. The B.1.617 variant is now in 44 countries. We don't yet know what that means for the global pandemic. Accessed May 12, 2021. https://edition.cn n.com/2021/05/12/world/coronavirus-newsletter-int 1-05-12-21/index.html

3. Ellis-Peterson H. "The system has collapsed": India's descent into Covid hell. Accessed May 13, 2021. https://www.theguardian.com/world/2021/apr/ 21/system-has-collapsed-india-descent-into-covid-h ell

4. BBC. WHO says India Covid variant of "global concern.” Accessed May 15, 2021. https://www.bbc.co $\mathrm{m} /$ news/world-asia-india-57067190\#: :text=The\%20 World\%20Health\%20Organization\%20(WHO,variant s\%20and\%20requires\%20further\%20study

5. Reuters. India's COVID-19 deaths cross quarter million as virus ravages countryside. Accessed May 17, 2021. https://www.dawn.com/news/1623477

6. Pandey V. India Covid: Delhi hospitals plead for oxygen as more patients die. Accessed May 13, 2021. https://www.bbc.com/news/world-asia-india-5694059 $\underline{5}$

7. Bhuyan A. COVID-19: India looks to import oxygen as cases surge, overwhelming hospitals. BMJ. Published online April 22, 2021:373. doi:10.1136/bm j.n1061

8. Kaul R. Rare infection is now an epidemic: Experts. Accessed May 21, 2021. https://www.hindustantime s.com/india-news/mucormycosis-a-rare-infection-bei ng-found-commonly-in-covid-patients-10162150280 3142.html

9. Pagano L, Ricci P, Tonso A, et al. Mucormycosis in patients with haematological malignancies: a retrospective clinical study of 37 cases. Br J Haematol. 1997;99(2):331-336. doi:10.1046/i.1365-2141.1997.39 83214.X

10. Prakash H, Chakrabarti A. Epidemiology of Mucormycosis in India. Microorganisms. 2021;9(3):523. doi:10.3390/microorganisms 9030523

11. Prakash H, Ghosh AK, Rudramurthy SM, et al. A prospective multicenter study on mucormycosis in India: Epidemiology, diagnosis, and treatment. Med Mycol. 2019;57(4):395-402. doi:10.1093/mmy/myy060
12. Majumdar K. A potentially lethal fungal disease is creeping into recovering COVID-19 patients, and the prognosis is not good. Accessed May 15, 2021. http s://www.businessinsider.in/science/health/news/a-po tentially-lethal-fungal-disease-is-creeping-into-reco vering-COVID-19-patients-and-the-prognosis-is-no t-good/articleshow/82476375.cms

13. Sharma S, Grover M, Bhargava S, Samdani S, Kataria T. Post coronavirus disease mucormycosis: a deadly addition to the pandemic spectrum. J Laryngol Otol. Published online 2021:1-6. https://www.ncbi.nl m.nih.gov/pmc/articles/PMC8060545/

14. Sen M, Lahane S, Lahane TP, Parekh R, Honavar SG. Mucor in a Viral Land: A Tale of Two Pathogens. Indian J Ophthalmol. 2021;69(2):244-252. doi:10.410 3/ijo.ijo 377420

15. Miller ME. Deadly 'black fungus' cases add to India's covid crisis. Accessed May 11, 2021. https://w ww.washingtonpost.com/world/2021/05/11/india-covi d-black-fungus/

16. Indian Council of Medical Research. Evidence based advisory in the time of COVID-19 (screening, diagnosis \& management of mucormycosis). Accessed May 2021. https://www.icmr.gov.in/pdf/covid/techdo c/Mucormycosis_ADVISORY_FROM_ICMR_In_COVID1 9 time.pdf

17. Talmi YP, Goldschmied-Reouven A, Bakon M, et al. Rhino-orbital and rhino-orbito-cerebral mucormycosis. Otolaryngol Head Neck Surg. 2002;127(1):22-31. doi:10.1067/mhn.2002.126587

18. Chakrabarti A, Singh R. Mucormycosis in India: unique features. Mycoses. 2014;57(3):85-90. doi:10.11 11/myc. 12243

19. Davey M. What is the deadly 'black fungus' seen in Covid patients in India? Accessed May 11, 2021. htt ps://www.theguardian.com/global/2021/may/11/wha t-is-the-dangerous-black-fungus-being-seen-in-covi d-patients-in-india-mucormycosis

20. Sen M. Black fungus: These 5 states account for over 65\% of India's 11,717 mucormycosis cases. Accessed May 21, 2021. https://www.livemint.com/ne ws/india/black-fungus-these-5-states-account-for-6 0-of-india-s-11-700-mucormycosis-cases-116220185 75067.html 
21. BusinessToday. Black Fungus cases on rise in Gujarat; state govt sets up separate wards for patients. Accessed May 18, 2021. https://www.busines stoday.in/current/economy-politics/black-fungus-cas es-on-rise-in-gujarat-state-govt-sets-up-separate-wa rds-for-patients/story/438608.html

22. Biswas S. Mucormycosis: The "black fungus" maiming Covid patients in India. Accessed May 13, 2021. https://www.bbc.com/news/world-asia-india-57 $\underline{027829}$

23. GAFFI. Doctors around the world call for rapid response to deadly mucormycosis (the so-called "black fungus") found in COVID patients in India. Accessed May 24, 2021. https://www.gaffi.org/doctor s-around-the-world-call-for-rapid-response-to-deadl y-mucormycosis-the-so-called-black-fungus-found-i n-covid-patients-in-india/

24. Slavin M, Thursky K. What is mucormycosis, the fungal infection affecting COVID patients in India? Accessed May 18, 2021. https://theconversation.com/ what-is-mucormycosis-the-fungal-infection-affectin g-covid-patients-in-india-160707
25. Biswas S. "White fungus": Drug-resistant fungal infections pose threat to India patients. Accessed June 6, 2021. https://www.bbc.com/news/world-asia-i ndia-57312832

26. Indian Express. Karnataka Covid-19 wrap: 5,783 new infections, 168 deaths; 2,856 black fungus cases till date. Accessed June 10, 2021. https://indianexpres s.com/article/cities/bangalore/karnataka-covid-19-inf ections-deaths-black-fungus-7365407/

27. Loke A. WHO World Diabetes Day. Accessed May 15, 2021. https://www.who.int/india/events/world-dia betes-day

28. Hindustan Times. Mucormycosis: Gujarat sets up special wards in hospitals, procures anti-fungal drug vials. Accessed May 13, 2021. https://www.hindustant imes.com/india-news/mucormycosis-gujarat-sets-upspecial-wards-in-hospitals-procures-anti-fungal-dru g-vials-101620550693969.html

29. Sarkar S. India should brace for third COVID-19 wave by Oct, say health experts. Accessed June 16, 2021. https://www.reuters.com/world/india/india-sho uld-brace-third-covid-19-wave-by-oct-say-health-ex perts-2021-06-18/ 